\title{
Natriuretic peptide receptors and heart failure: to B or not to B blocked?
}

\author{
A. J. Hobbs
}

Received: 19 November 2013 / Accepted: 26 November 2013 /Published online: 6 December 2013

(C) Springer-Verlag Berlin Heidelberg 2013

The role of natriuretic peptides in the dynamic regulation of blood volume and pressure is now well established and comprises the complementary endocrine actions of atrial (ANP) and brain (BNP) natriuretic peptides, with the more local, paracrine bioactivity of C-type natriuretic peptide (CNP). This family of mediators also coordinates to maintain cardiac function and integrity (Potter et al. 2009). However, much of the information pertaining to the physiological functions of these peptides has not been garnered via the use of selective pharmacological tools. Indeed, there are a paucity of such reagents and this has been the bane of researchers in the field for their inception with the identification of ANP in 1981(de Bold et al. 1981). Several selective agonists and antagonists at natriuretic peptide receptors (NPRs), the membrane spanning proteins that transduce signals conveyed by natriuretic peptides, have been described, but the vast majority are high molecular weight, often peptide-based, molecules with suboptimal pharmacodynamic and pharmacokinetic properties.

Perhaps the most useful tool to date has been HS-142-1, a polysaccharide extracted from Aureobasidium sp. (Morishita et al. 1991). This reagent inhibits activation of both guanylate cyclase-coupled NPRs (i.e. NPR-A and NPR-B) through an allosteric interaction, but does not bind NPR-C (Poirier et al. 2002). It has therefore been an ideal intervention to define mechanisms reliant on the activation of particulate guanylate cyclases (and to differentiate between these membrane-bound isoforms and the NO-sensitive soluble guanylate cyclase). Regrettably, the production of HS-142-1 has now been halted and is no longer available. Several additional molecules

\section{A. J. Hobbs ( $\square)$}

William Harvey Research Institute, Barts \& The London School

of Medicine \& Dentistry, Queen Mary University of London,

Charterhouse Square, London EC1M 6BQ, UK

e-mail: a.j.hobbs@qmul.ac.uk have been reported to selectively inhibit NPR-A (the cognate receptor for ANP and BNP, e.g. A71915 (Delporte et al. 1992), S-28-Y (Minamitake et al. 1990), anantin (Weber et al. 1991; Wyss et al. 1991) and PL-3994 (Edelson et al. 2013)) or NPR-B (the cognate receptor for CNP, e.g. a monoclonal antibody 3G12 (Drewett et al. 1995) and P19 (Deschenes et al. 2005)). A truncated, modified natriuretic peptide, $\mathrm{CANF}^{4-23}$, has been established as a useful pharmacological tool for dissecting the biology of NPR-C. Originally, it was used to identify NPR-C binding sites in vivo and subsequently shown to block the clearance of natriuretic peptides from the circulation (Maack et al. 1987). However, this peptide also has positive signalling roles, courtesy of the Gi coupling of NPR-C (Anand-Srivastava et al. 1996); thus, $\mathrm{CANF}^{4-23}$ may well represent a partial agonist at this receptor. Additional molecules described as selective NPR-C antagonists have been developed more recently (e.g. AP-811, M372049 (Veale et al. 2000)) and used to establish the importance of endothelium-derived CNP in regulating vascular reactivity in vitro (Chauhan et al. 2003).

As a consequence of the various shortcomings of these molecules (e.g. source, cost, solubility, selectivity and route of administration), they have either been unavailable or not readily amenable for use in vivo, and many of the physiological roles of natriuretic peptides have only been established unequivocally with the recent development of global and tissue-specific transgenic animals. Good examples of this are the cardiac hypertrophy and fibrosis in ANP- and BNP-deficient mice (Kuhn 2009) and the perturbed bone homeostasis and dwarfism in mice lacking the CNP (Nppc) gene (Chusho et al. 2001). However, whilst pharmacological tools have not been used avidly to dissect the physiological and pathological roles of natriuretic peptides, the administration of native or synthetic natriuretic peptides has been far more successful in terms of therapeutic intervention. ANP (carperitide) and BNP (nesiritide) are used in the treatment of heart failure, but with limited efficacy, 
predominantly due to reductions in systemic blood pressure and renal perfusion. Novel chimeric peptides, which harness several favourable actions by combining portions from two or more native natriuretic peptides, perhaps hold greater promise (Lisy et al. 2008; Dickey et al. 2008). For example, CD-NP (cenderitide) consists of CNP with an additional 15aa corresponding to the C-terminal tail of DNP. This peptide activates both NPR-A and NPR-B and promotes the venodilatory, antifibrotic properties of CNP in tandem with the natriuretic properties of DNP (the peptide is also more resistant to enzymatic degradation) without the therapeutically limiting hypotensive response. CD-NP had a favourable pharmacodynamic profile in phase I (Lee et al. 2009), and in a small phase IIa safety and tolerability study (Lieu et al. 2011), and is currently under phase IIb evaluation. A similar favourable pharmacodynamic profile has also been established for a mutant ANP consisting of the native peptide with a $\mathrm{C}$-terminal 12aa extension (McKie et al. 2009)

However, the dearth of small molecule, receptor-selective NPR tools (and ultimately therapeutics) may have come to an end with the report by Bach et al. in this issue. This work describes the development of a high-throughput screen to identify non-peptidic, small-molecule antagonists at NPR-B. Using HEK293 cells transfected with human NPR-A or NPR$\mathrm{B}$ cDNA, and cGMP production as functional read-out, the authors have identified a series of compounds that block NPR$B$ and exhibit discernible selectivity over NPR-A. The ex vivo pharmacology of the novel small molecules was confirmed using rat myocardial muscle strips in which $\mathrm{C} 10$, one of the compounds with greatest antagonist potency at NPR-B, was shown to inhibit the CNP-driven potentiation of inotropic responses to $\beta 1$-adrenoceptor activation. The novel NPR-B antagonists exert a non-competitive, reversible antagonism (little or no change in the $\mathrm{EC}_{50}$ to $\mathrm{CNP}$ but a signification reduction in $E_{\max }$ ), suggesting allosteric modulation of the receptor, conceivably akin to that produced by HS-142-1. Further work is now needed to define this binding site. A crystal structure for NPR-B has not been reported, but cocrystals with these new molecules, in tandem with molecular data, might reveal a new allosteric site on NPR-B (and possibly mirrored by other NPRs) that is tractable for therapeutic benefit. One important unknown for the utility of these molecules as tools and therapeutics is binding and activity at NPR-C. Whether they can act as NPR-C agonists and mimic some of the beneficial effects of CNP in the cardiovascular system we have reported (Chauhan et al. 2003) remains to be determined. Nonetheless, even if these novel compounds bound tightly to NPR-C and prevent clearance of endogenous natriuretic peptides, this might also be construed as a beneficial activity, certainly in disorders such as pulmonary hypertension in which augmenting NP bioactivity has been proven to be beneficial in experimental models and humans (Baliga et al. 2008; Klinger et al. 2006).
In addition, this work has identified molecules that exhibit antagonist activity at NPR-B, but potentiate BNP-triggered activation of NPR-A (although the molecules do not appear to be NPR-A agonists per se). This is an intriguing profile of activity since activation of NPR-A is established to result in a positive effect in preclinical models and patients with different cardiovascular diseases, including heart failure, renal I/R injury and pulmonary hypertension, and may therefore offer an even greater therapeutic effect. Moreover, the structure-activity relationship (SAR) data from this study intimates that relatively minor and readily achievable modifications to this series of molecules can generate compounds with very different activity and selectivity at NPRs. Thus, this work should be an excellent starting point for the development of small molecules that can target specific NPRs that might be useful in a plethora of cardiovascular disorders. Interestingly, one of the molecules shown to modulate NPR-B activity, C37, was subsequently identified as loperamide (an opioid receptor agonist with antidiarrhoeal activity). Since this compound was shown to block NPR-B activation by CNP, it may well interact with the intestinal epithelium guanylate cyclase $\mathrm{C}$ (GG-C), which regulates salt and water excretion. This raises the fascinating possibility that part of the therapeutic effect of loperamide might be mediated via GC-C and that this work might stimulate the development of small molecules with therapeutic potential outside the cardiovascular system.

The rationale for the development of NPR-B antagonists is derived from previous work by the authors exploring the cardiac contractility effects of CNP in normal versus failing hearts. Using isolated myocardial strips, these authors have shown that CNP causes an increase in cGMP, via NPR-B, that leads to inhibition of PDE3 thereby promoting the actions of catecholamine-driven cAMP signalling, which exerts positive inotropic and chronotropic activities (Qvigstad et al. 2010). This is considered detrimental to the failing heart, with pharmacological inhibition of PDE3 associated with increased mortality (Packer et al. 1991; Amsallem et al. 2005). This fits with other reports in ex vivo systems showing that CNP can exert a positive inotropic activity (Pierkes et al. 2002). Thus, blockade of NPR-B may be a favourable approach in heart failure. However, the net effect of NPR-B antagonism in vivo may not be so clear cut. In rats over-expressing a dominant negative form of NPR-B in cardiomyocytes, development of cardiac hypertrophy, fibrosis and contractile dysfunction is accelerated compared to WT animals (Langenickel et al. 2006). Moreover, there appears to be a shift from NPR-A to NPR-B signalling in pressure-overload-induced cardiac hypertrophy, suggesting that CNP takes on the principal role as the natriuretic peptide guardian of cardiac integrity (Dickey et al. 2007). This concept is reinforced by the observations that cardiomyocyte-specific over-expression of CNP protects against MI-induced hypertrophy (Wang et al. 2007) and that CD-NP exerts a potent salutary effect in a preclinical 
model of cardiac fibrosis (Martin et al. 2012). Finally, systemic administration of a NPR-B targeted drug would have to be evaluated carefully for effects on bone morphology (Chusho et al. 2001).

Regardless, the work reported by Bach et al. is an exciting and welcome addition to the pharmacology of natriuretic peptides and their receptors and should pave the wave for the design and development of more selective molecules that have new, unique activities across the NPR spectrum and should prove vital in advancing knowledge of the role of these receptors in mediating the biological activity of natriuretic peptides and in the pursuit of better therapeutics for cardiovascular disease.

\section{References}

Amsallem E, Kasparian C, Haddour G, Boissel JP, Nony P (2005) Phosphodiesterase III inhibitors for heart failure. Cochrane Database Syst (1):RevCD002230

Anand-Srivastava MB, Sehl PD, Lowe DG (1996) Cytoplasmic domain of natriuretic peptide receptor-C inhibits adenylyl cyclase. Involvement of a pertussis toxin-sensitive $\mathrm{G}$ protein. J Biol Chem 271:19324-19329

Baliga RS, Zhao L, Madhani M, Lopez-Torondel B, Visintin C, Selwood D, Wilkins MR, MacAllister RJ, Hobbs AJ (2008) Synergy between natriuretic peptides and phosphodiesterase 5 inhibitors ameliorates pulmonary arterial hypertension. Am J Respir Crit Care Med 178: 861-869

Chauhan SD, Nilsson H, Ahluwalia A, Hobbs AJ (2003) Release of Ctype natriuretic peptide accounts for the biological activity of endothelium-derived hyperpolarizing factor. Proc Natl Acad Sci U S A 100:1426-1431

Chusho H, Tamura N, Ogawa Y, Yasoda A, Suda M, Miyazawa T, Nakamura K, Nakao K, Kurihara T, Komatsu Y, Itoh H, Tanaka K, Saito Y, Katsuki M, Nakao K (2001) Dwarfism and early death in mice lacking C-type natriuretic peptide. Proc Natl Acad Sci U S A 98:4016-4021

de Bold AJ, Borenstein HB, Veress AT, Sonnenberg H (1981) A rapid and potent natriuretic response to intravenous injection of atrial myocardial extract in rats. Life Sci 28:89-94

Delporte C, Winand J, Poloczek P, Von GT, Christophe J (1992) Discovery of a potent atrial natriuretic peptide antagonist for ANPA receptors in the human neuroblastoma NB-OK-1 cell line. Eur J Pharmacol 224:183-188

Deschenes J, Dupere C, McNicoll N, L'Heureux N, Auger F, Fournier A, Lean AD (2005) Development of a selective peptide antagonist for the human natriuretic peptide receptor-B. Peptides 26:517-524

Dickey DM, Flora DR, Bryan PM, Xu X, Chen Y, Potter LR (2007) Differential regulation of membrane guanylyl cyclases in congestive heart failure: NPR-B, not NPR-A, is the predominant natriuretic peptide receptor in the failing heart. Endocrinologyen 148(7):3518-3522

Dickey DM, Burnett JC Jr, Potter LR (2008) Novel bifunctional natriuretic peptides as potential therapeutics. J Biol Chem 283:3500335009. doi:10.1074/jbc.M804538200

Drewett JG, Fendly BM, Garbers DL, Lowe DG (1995) Natriuretic peptide receptor-B (guanylyl cyclase-B) mediates C-type natriuretic peptide relaxation of precontracted rat aorta. J Biol Chem 270: $4668-4674$
Edelson JD, Makhlina M, Silvester KR, Vengurlekar SS, Chen X, Zhang J, Koziol-White CJ, Cooper PR, Hallam TJ, Hay DW, Panettieri RA $\mathrm{Jr}$ (2013) In vitro and in vivo pharmacological profile of PL-3994, a novel cyclic peptide (Hept-cyclo(Cys-His-Phe-d-Ala-Gly-Arg-dNle-Asp-Arg-Ile-Ser-Cys)-Tyr-[Arg mimetic]-NH(2)) natriuretic peptide receptor-A agonist that is resistant to neutral endopeptidase and acts as a bronchodilator. Pulm Pharmacol Ther 26:229-238. doi: 10.1016/j.pupt.2012.11.001

Klinger JR, Thaker S, Houtchens J, Preston IR, Hill NS, Farber HW (2006) Pulmonary hemodynamic responses to brain natriuretic peptide and sildenafil in patients with pulmonary arterial hypertension. Chest 129:417-425

Kuhn M (2009) Function and dysfunction of mammalian membrane guanylyl cyclase receptors: lessons from genetic mouse models and implications for human diseases. Handb Exp Pharmacol 191: 47-69. doi:10.1007/978-3-540-68964-5 4

Langenickel TH, Buttgereit J, Pagel-Langenickel I, Lindner M, Monti J, Beuerlein K, Al-Saadi N, Plehm R, Popova E, Tank J, Dietz R, Willenbrock R, Bader M (2006) Cardiac hypertrophy in transgenic rats expressing a dominant-negative mutant of the natriuretic peptide receptor B. Proc Natl Acad Sci U S A 103: 4735-4740

Lee CY, Chen HH, Lisy O, Swan S, Cannon C, Lieu HD, Burnett JC Jr (2009) Pharmacodynamics of a novel designer natriuretic peptide, CD-NP, in a first-in-human clinical trial in healthy subjects. J Clin Pharmacol 49:668-673

Lieu HD, Young J, Elkayam U, Katz A, Darius H, Goldstein S, Massie B, Costello-Boerrigter LC, Burnett JC (2011) A phase II, dose-ranging study with CD-NP, a chimeric natriuretic peptide, in acute decompensated heart failure patients with renal compromise. J Am Coll Cardiol 57(14s1):4-5, E2029

Lisy O, Huntley BK, McCormick DJ, Kurlansky PA, Burnett JC Jr (2008) Design, synthesis, and actions of a novel chimeric natriuretic peptide: CD-NP. J Am Coll Cardiol 52:60-68

Maack T, Suzuki M, Almeida FA, Nussenzveig D, Scarborough RM, McEnroe GA, Lewicki JA (1987) Physiological role of silent receptors of atrial natriuretic factor. Science 238:675-678

Martin FL, Sangaralingham SJ, Huntley BK, McKie PM, Ichiki T, Chen HH, Korinek J, Harders GE, Burnett JC Jr (2012) CD-NP: a novel engineered dual guanylyl cyclase activator with anti-fibrotic actions in the heart. PLoS One 7:e52422. doi:10.1371/journal.pone. 0052422

McKie PM, Cataliotti A, Huntley BK, Martin FL, Olson TM, Burnett JC Jr (2009) A human atrial natriuretic peptide gene mutation reveals a novel peptide with enhanced blood pressurelowering, renal-enhancing, and aldosterone-suppressing actions. J Am Coll Cardiol 54:1024-1032. doi:10.1016/j.jacc.2009.04.080

Minamitake Y, Furuya M, Kitajima Y, Takehisa M, Tanaka S (1990) Synthesis and biological property of alpha-human atrial natriuretic peptide analogs with a constrained or stereochemically modified cyclic moiety. Chem Pharm Bull (Tokyo) 38:1920-1926

Morishita Y, Sano T, Ando K, Saitoh Y, Kase H, Yamada K, Matsuda Y (1991) Microbial polysaccharide, HS-142-1, competitively and selectively inhibits ANP binding to its guanylyl cyclase-containing receptor. Biochem Biophys Res Commun 176:949-957

Packer M, Carver JR, Rodeheffer RJ, Ivanhoe RJ, DiBianco R, Zeldis SM, Hendrix GH, Bommer WJ, Elkayam U, Kukin ML (1991) Effect of oral milrinone on mortality in severe chronic heart failure. The PROMISE Study Research Group. N Engl J Med 325:14681475. doi:10.1056/NEJM199111213252103

Pierkes M, Gambaryan S, Boknik P, Lohmann SM, Schmitz W, Potthast R, Holtwick R, Kuhn M (2002) Increased effects of C-type natriuretic peptide on cardiac ventricular contractility and relaxation in guanylyl cyclase A-deficient mice. Cardiovasc Res 53:852-861

Poirier H, Labrecque J, Deschenes J, DeLean A (2002) Allotopic antagonism of the non-peptide atrial natriuretic peptide (ANP) antagonist 
HS-142-1 on natriuretic peptide receptor NPR-A. Biochem J 362: 231-237

Potter LR, Yoder AR, Flora DR, Antos LK, Dickey DM (2009) Natriuretic peptides: their structures, receptors, physiologic functions and therapeutic applications. Handb Exp Pharmacol (191): 341-366

Qvigstad E, Moltzau LR, Aronsen JM, Nguyen CH, Hougen K, Sjaastad I, Levy FO, Skomedal T, Osnes JB (2010) Natriuretic peptides increase beta1-adrenoceptor signalling in failing hearts through phosphodiesterase 3 inhibition. Cardiovasc Res 85:763-772. doi: 10.1093/cvr/cvp364

Veale CA, Alford VC, Aharony D, Banville DL, Bialecki RA, Brown FJ, Damewood JR Jr, Dantzman CL, Edwards PD, Jacobs RT, Mauger RC, Murphy MM, Palmer W, Pine KK, Rumsey WL, GarciaDavenport LE, Shaw A, Steelman GB, Surian JM, Vacek EP (2000)
The discovery of non-basic atrial natriuretic peptide clearance receptor antagonists. Part 1. Bioorg Med Chem Lett 10:1949-1952

Wang Y, de Waard MC, Sterner-Kock A, Stepan H, Schultheiss HP, Duncker DJ, Walther T (2007) Cardiomyocyte-restricted overexpression of C-type natriuretic peptide prevents cardiac hypertrophy induced by myocardial infarction in mice. Eur J Heart Fail 9: 548-557

Weber W, Fischli W, Hochuli E, Kupfer E, Weibel EK (1991) Anantin — a peptide antagonist of the atrial natriuretic factor (ANF). I. Producing organism, fermentation, isolation and biological activity. J Antibiot (Tokyo) 44:164-171

Wyss DF, Lahm HW, Manneberg M, Labhardt AM (1991) Anantin-a peptide antagonist of the atrial natriuretic factor (ANF). II. Determination of the primary sequence by NMR on the basis of proton assignments. J Antibiot (Tokyo) 44:172-180 